\title{
A decision model for IS outsourcing
}

\author{
Chyan Yang*, Jen-Bor Huang \\ Institute of Business and Management, National Chiao Tung University, 4F, 114, Section 2, \\ Chung Hsiqo W. Road, Taipei, Taiwan, ROC
}

\begin{abstract}
Information systems outsourcing has been one of the critical issues facing IS management recently, but it still stays in the stage of conceptual discussion about how to outsource the IS activities. The determinants used so far, for instance, transaction costs and "strategic" or "commodities" characteristics, are too narrow to help the end users determine if their system should be outsourced. This paper argues that five factors, including management, strategy, economics, technology and quality, should be considered for outsourcing decisions. Furthermore, the paper proposes a decision model, which uses the analytic hierarchy process (AHP) method to help users in structuring the outsourcing problems. The decision model generates numeric values for users to decide whether they should adopt the outsourcing strategy for each IS systems under consideration. (C) 2000 Elsevier Science Ltd. All rights reserved.
\end{abstract}

Keywords: Information systems outsourcing; Transaction cost economics; Analytic hierarchy process

\section{Introduction}

\subsection{IS outsourcing background}

The practice of information system outsourcing began in 1954 when General Electric Corp. contracted with Arthur Andersen and Univac (Klepper \& Jones, 1998). Ketler and Walstrom (1993) argued that there were different IS problems and distinct form of outsourcing from 1960s to the 1990s, which are summarized in Table 1.

Several aspects of outsourcing in 1990s are different from those of 1970s and 1980s. They include that larger companies are outsourcing, a greater range and depth of services are being outsourced,

\footnotetext{
*Corresponding author. Tel.: + 886-357-26204; fax: + 886-357-23792.

E-mail addresses: cyang@cc.cc.nctu.edu.tw (C. Yang), jbhuang@iii.org.tw (J. B. Huang).
} 
Table 1

IS problems and outsourcing form ${ }^{\mathrm{a}}$

\begin{tabular}{lll}
\hline Time & Problem & The form of outsourcing \\
\hline $1960 \mathrm{~s}$ & $\begin{array}{l}\text { Cost of hardware } \\
\text { Expense of software development } \\
\text { (Lack of IS personnel and high demand } \\
\text { of IS applications) }\end{array}$ & $\begin{array}{l}\text { Facilities or operation management } \\
\text { Contract programming } \\
\text { (In house) }\end{array}$ \\
Early 1990s & $\begin{array}{l}\text { To support vertical integration } \\
\text { On site facilities management and complete out- } \\
\text { sourcing }\end{array}$ \\
\hline
\end{tabular}

a(Source: Ketler \& Walstrom, 1993).

service providers are accepting management responsibility and risk, and the nature of the relationship with the service provider is changing (Grover, Joong, Cheon \& Teng, 1996).

Other characteristics of current IS outsourcing practice are the huge amount of money and duration of the deal involved. The megadeal that Xerox awarded EDS, a 10 year $\$ 3.2$ billion outsourcing contract in June 1994, is the largest one ever seen so far (Caldwell, 1995). Moreover, the magnitude of the growth of IS outsourcing market surprises many experts. International Data Corporation (IDC) predicted that the worldwide outsourcing market would grow from $\$ 100$ billion in 1998 to $\$ 151$ billion in the year 2003 with a 12.2\% CAGR (Murphy, Ker \& Ross, 1999). The US market is expected to expand from \$51.5 billion in 1998 to \$81 billion in 2003 (Murphy et al., 1999). In Asia, for example in Taiwan, the outsourcing market is just emerging. In an investigation conducted by Directorate General of Budget, Accounting and Statistics (DGBAS) Executive Yuan, ROC to 1893 firms in 1998, the total amount of outsourcing was 205 million US dollars and the growth rate was $27 \%$ (DGBAS, 1998). Recently, the Government is promoting the concept of outsourcing and is encouraging public enterprises to outsource the IS functions or even the entire department. The market is predicted to grow rapidly in the near future.

There are many ways to examine IS outsourcing, depending on the viewpoints of researchers. For instance, IS functions are just simply classified into system operation and software development (Aubert, Rivard \& Patry, 1996) or are classified into system integration, facility management, contract programming, software support, network maintenance, minicomputer maintenance, mainframe maintenance, and workstation/PC maintenance (Arnett \& Jones, 1994). Additionally, Takac categorized outsourcing as network service, service retention, service transfer and asset transfer (Takac, 1994). Grover et al. (1996) divided it into application development and maintenance, system operation, networks/telecommunications management, end-user computing support, systems planning and management, and purchase of application software.

Researchers have proposed many definitions of outsourcing. One of the most accepted definitions is "the significant contribution by external vendors in the physical and/or human resources associated with the entire or specific components of the IT infrastructure in the user organization" (Loh \& Venkatraman, 1992). Other researchers defined it as "the transfer of assets - computers, networks and people - from a user to vendor, the vendor is taking over the responsibility for the outsourced activity" (Takac, 1994), "an act of subcontracting a part, or all of an organizations IS 
work to external vendor(s), to manage on its behalf" (Altinkemer, Chaturvedi \& Gulati, 1994). Willcocks, Lacity and Fitzgerald (1995) defined it as "handing over to third-party management, for required result, some or all of an organizations IT information system (IS) and related service". Grover et al. (1996) defined it as "practice of turning over part or all of an organizations IS function to external service provider(s)". There exists no major differences among these definitions, which encompass three components: first, external provider takes over part or all of an organizations IS functions; second, external provider should take the responsibility; and third, customers transfer IS functions to external provider as well as employee and part of computer facilities.

The causes for the fast growth of IS outsourcing market are due to firms trying to reduce cost and to increase productivity as well as the change of external environments. First, before 1980, to support vertical integration, it was more suitable to develop IS systems internally. Due to the maturing of information technology, scale of economics from external provider and the desire to reduce cost (Smith, Mitra \& Narasimhan, 1998), the IS outsourcing market boomed from 1980. Second, because of the violent global competition, firms need more focus on core competence. It is necessary to get services from outside for their commodity IS. Third, the lack of human resources force firms to outsource more of their IT functions. Research by Rosenthal and Jategaonkare (1995) found that the number of students interested in management information system discipline were decreasing. On the other hand, the demands for human resources are rapidly increasing. Fourth, rapid changes of information technology drive firms to get new technology from outside providers (Slaughter \& Ang, 1996). Fifth, in addition, the notion of outsourcing is rapidly shifting from parts, components, and hardware subsystems toward a service-based economy with more intellectual focus. Firms need to obtain the knowledge that they did not ever have to stay up current and even more competitively (Quinn, 1999). The pace of change and advancement in environment and technology are ever increasing. Firms that cannot adapt suitable strategy and get the latest application of technology would be left behind.

Recently, the growth of Internet usage stimulates the fast growth of electronic commerce. Firms think that Internet and electronic commerce are powerful tools for business growth (Bourassa, 1998). The business-to-business market was more than $\$ 43$ billion in 1998 and was projected by Forrester Research to reach $\$ 1.3$ trillion at the end of 2002 (Flanagan, 1999).

Nevertheless, it is not easy for a firm to set up and maintain a computing environment composed of a myriad of technologies. Firms must invest heavily to recruit IT professionals and demand sufficient bandwidth especially, when website traffic unexpectedly explodes, reliability and flexibility are critical. E-Bay lost $\$ 3$ million- $\$ 5$ million in revenues when its site crashed and stayed down for almost 24 hours in June 1992 (Flanagan, 1999).

Considering that the electronic commerce is becoming a critical strategy for firms avoiding to deal with the difficult situation, it makes sense to look outside the enterprise for building up and maintaining the website. Outsourcing, again, is considered a powerful means of solving such problems.

The reminder of this paper is organized as follows. In Section 2, we review some relevant outsourcing decision considerations and strategies that have been proposed by researchers before. In Section 3, we build an AHP model in three steps. First, we make some assumptions for building this model. Second, we propose five factors, which need to be considered when making the outsourcing decision. Third, we present five steps of establishing a model by an example. Finally, in Section 4, we discuss the research findings with implications for future practice. 


\subsection{The research problems and goals}

In spite of the continuing expansion of outsourcing markets and the awareness of the strategic position IS outsourcing occupies, there are issues facing firms when they consider the outsourcing strategy. What kinds of information systems should be outsourced? How to decide the priority of those IS which have been decided to outsource?

IS outsourcing is a new issue facing information management. Until now, there are no quantitative decision models which can help a practitioner with outsourcing an IS. The goal of this paper is to offer a quantitative decision model that can help practitioners set priority and reap the most benefits from outsourcing.

\section{Literature review}

\subsection{Theoretical background}

The theoretical foundation of outsourcing most frequently mentioned is transaction cost economics introduced by Coase (1937). The transaction cost economics, sometimes called transaction cost theory, was developed principally by Williamson $(1975,1979,1985)$. Arrow (1969) used the "transaction cost" first and defined it as "costs of running the economic system" (Dietrich, 1994). When Coase (1937) proposed that "the main reason why it is profitable to establish a firm would seem to be that there is a cost of using the price mechanism", the effect was that many industries sought supports outside (Grover et al., 1996). Williamson (1979) defined the transaction costs as ex ante and ex post transaction costs. Ex ante transaction costs are the costs of drafting, negotiating and safeguarding an agreement. Ex post transaction costs include the maladaption costs, haggling cost, the setup and running costs, and the bonding costs. Lacity and Hirschheim (1993) thought that they consist of the costs of monitoring, controlling, and managing transactions.

Williamson (1979) followed the transaction cost economics to propose the transaction governance structures (Table 2), which use two factors, frequency and investment specificity, to help managers with deciding if the systems would adopt hierarchy choice or market choice. Frequency refers to how often a transaction occurs. Investment specificity refers to the degree of customization of the transactions, including site specificity, physical asset specificity or human asset specificity.

Table 2

Transaction governance structures ${ }^{\mathrm{a}}$

\begin{tabular}{llll}
\hline Frequency & Investment characteristics & & Idiosyncratic \\
\cline { 2 - 4 } & Nonspecific & Mixed & Trilateral governance \\
$\begin{array}{l}\text { Occasional transaction } \\
\text { Recurrent transaction }\end{array}$ & Market governance & Bilateral governance & Unified governance \\
\hline
\end{tabular}

a(Source: Williamson, 1979, p. 253). 
A transaction which occurs within the firm is called the hierarchy choice, and a transaction occuring between the firm and a vendor is called market choice (Lacity \& Hirschheim, 1993). From transaction governance structures, only unified governance belongs to the hierarchy choice and the transaction is produced by means of vertical integration internally. By transaction cost economics, only the transaction, which is idiosyncratic and recurrent, is worthy to be produced by unified governance which means to produce it internally. For other cases, organizations should choose the market choice alternatives and sign an appropriate contract to reduce the opportunism. Opportunism means "self-interest seeking with guile." It happens because only a few vendors exist in the market (Williamson, 1985).

In order to avoid opportunism, outsourcers should consider multiple competing vendors strategy. Ngwenyama and Bryson (1999) presented an approach by using transaction cost concepts to modeling the key aspects of single- and multi-vendor outsourcing strategies and find the minimum cost and maximum possible profit for each strategy. In addition, it provides information, which can be used to structure incentive schemes to induce the vendor to achieve higher levels of performance.

Another generic method, which came from manufacturing industries, to determine whether IS functions should be outsourced is to differentiate the IS functions as strategic or commodity. The strategic sourcing process, which is proposed by Venkatesan (1992), suggests that manufacturing industry should distinguish between strategic operations and commodity operations of producing components and outsource the commodity operations.

Many researchers have proposed various outsourcing strategies. Lacity, Willcocks and Feeny (1996) argued that deciding the outsourcing of IS activities just by strategic or commodities is fallacious and senior executives may mistakenly classify all IT activities as commodities. Therefore, they presented a decision matrix using the business, economic, and technical factors. Buck-lew (1992) distinguished between pure outsourcing and hybrid outsourcing and thought that managers should use technical, project management, business and organization factors to decide which IS functions should be outsourced. Ketler and Walstrom (1993) suggested that variables for evaluating outsourcing decisions could be categorized as personal, economic, risk versus control, characteristics of outsourced data/segment, organizational characteristics, and vender and contract issues. Grover, Joong, Cheon and Teng (1994) think that the success of outsourcing can be assessed in terms of attainment of benefits. These can be described in three categories: strategic benefit, economic benefit, and technological benefit. McFarlan and Nolan (1995) proposed a "strategic grid" framework to judge when the IS functions need to be outsourced.

Although researchers put so many outsourcing decision strategies and determinants to practitioners, the current practice remains in the stage of conceptual discussion as to how to outsource the IS activities. Furthermore, these strategies and determinants cannot offer a quantitative magnitude for judgement. Some strategies or determinants, for instance, transaction cost or systems that are "strategic" or "commodities," are too narrow to help the practitioners determine if their systems could be outsourced or to examine the priorities among many potential outsourcing systems. Ineffective outsourcing activities, derived from improper strategy or methods, would damage the firm and shatter end-user confidence.

The outsourcing decision should consider the various factors, including tangible (such as cost, facilities, human resources) and intangible (such as strategy, quality) factors. The decision process should include clear, coherent analytic steps and can generate numerical results to convince those who involved accepting the result. In 1971, Saaty developed an analytic method, namely the 
analytic hierarchy process (AHP), which has the characteristics that we need for making outsourcing decisions.

\subsection{Analytic hierarchy process}

AHP, developed by Tomas L. Saaty (1980), mainly addresses how to solve decision problems with uncertainty and with multiple criteria characteristics.

AHP is a method that collects expertise of decision-makers and uses a hierarchic structure to present a complex decision problem by decomposing it into several smaller subproblems. By using pairwise comparisons, we can derive a square matrix from the hierarchy, and we can find the eigenvector with the largest eigenvalue. The eigenvector provides the priority ordering and the eigenvalue is a measure of the consistency of judgement. The AHP method encompasses three steps: first, constructing the hierarchy; second, computing the weight of the elements in each level; and third, computing the weight of alternatives.

\subsubsection{Construct the hierarchy}

A complex problem can be dealt with by decomposing it into subproblems within hierarchy. The elements in a level of hierarchy would not exceed seven, because it is difficult for human beings to deal with more than seven things simultaneously. The highest level with only one element is the goal we want to reach, and the elements in the lowest level are the alternatives or activities. Elements in the middle levels are the criteria or attributes for evaluating those alternatives.

\subsubsection{Compute the weight of the elements in each level}

Three steps can describe this phase: Paired comparisons, computing a vector of priorities, and measuring consistency.

(a) Paired comparisons: The elements in a level of the hierarchy are compared in terms of their importance or contribution to a given criterion that occupies the level immediately above the elements being compared. It requires comparison of $n(n-1) / 2$ times if the number of elements are $n$. The numbers used for comparison are $\frac{1}{9}, \frac{1}{8}, \ldots \frac{1}{2}, 1,2,3, \ldots 8,9$. The meaning of the numbers are shown in Table 3.

The magnitudes we get from paired comparison would be put into the upper triangle of the square matrix, the main diagonal of the matrix must consist of 1's, the magnitudes of the down triangle would be the reciprocals of the reverse position in the matrix. Based on symbols of mathematics, it can be expressed as follows:

Let $C_{1}, C_{2}, \ldots C_{w}$ be the set of criteria or attributes. The quantified comparisons on pairs $C_{i}, C_{j}$ can be represented by an $n \cdot n$ matrix:

$$
A=\left(a_{i j}\right),(i, j=1, \ldots, n) \text { and if } a_{i j}=a \text {, then } a_{j i}=1 / a \text {, and } a_{i j}=1 \text { if } i=j .
$$

(b) Computing a vector of priorities: We can compute the principal eigenvector, which becomes the vector of priorities when normalized. The formula to get the principal eigenvector is

$$
A w=\lambda_{\max } w, \lambda_{\max } \text { is the largest eigenvalue of } A, w \text { is the eigenvector. }
$$

(c) Measuring consistency: It may be difficult for decision makers to reach consistency in the process of deriving the positive reciprocal matrix. A measure of consistency of the given pairwise 
Table 3

AHP scale and meaning ${ }^{\mathrm{a}}$

\begin{tabular}{|c|c|c|}
\hline Intensity of importance & Definition & Explanation \\
\hline 1 & Equal importance & $\begin{array}{l}\text { Two activities contribute equally to the } \\
\text { objective }\end{array}$ \\
\hline 3 & Weak importance of one over another & $\begin{array}{l}\text { Experience and judgment slightly favor } \\
\text { one activity over another }\end{array}$ \\
\hline 5 & Essential or strong importance & $\begin{array}{l}\text { Experience and judgment strongly favor } \\
\text { one activity over another }\end{array}$ \\
\hline 7 & Very strong or demonstrated importance & $\begin{array}{l}\text { An activity is favored very strongly over } \\
\text { another; its dominance demonstrated in } \\
\text { practice }\end{array}$ \\
\hline 9 & Absolute importance & $\begin{array}{l}\text { The evidence favoring one activity over } \\
\text { another is of the highest possible order } \\
\text { of affirmation }\end{array}$ \\
\hline $2,4,6,8$ & $\begin{array}{l}\text { Intermediate values between adjacent } \\
\text { scale values }\end{array}$ & When compromise is needed \\
\hline Reciprocals of above nonzero & $\begin{array}{l}\text { If activity } i \text { has one of the above } \\
\text { nonzero numbers assigned to it when } \\
\text { compared with activity } j \text {, then } j \text { has the } \\
\text { reciprocal value when compared with } i\end{array}$ & A reasonable assumption \\
\hline Rationales & $\begin{array}{l}\text { Intermediate values between adjacent } \\
\text { scale values }\end{array}$ & When compromise is needed \\
\hline
\end{tabular}

${ }^{\mathrm{a}}$ (Source: Saaty, 1980).

comparison is needed. Consistency means $a_{i j} \cdot a_{j k}=a_{i k}$. The consistency ratio (CR) provides a measure of the probability that the matrix was filled in purely at random. The number 0.1 is the accepted upper limit for CR (Harker, 1989). The measurement of consistency can be used to evaluate the consistency of decision makers as well as the consistency of all the hierarchy.

\subsubsection{Computing the weight of alternatives}

We can compute the weight of lower level after computing that of current level. Once reaching the lowest level, we can obtain the overall ranking by adding the results of the weight of criteria multiplied by the weight of alternatives.

Assume that the relative importance of $m$ alternatives have to be established by $n$ criteria. Let $C_{i}$ $(i=1, \ldots, n)$ be the weight of criteria $i, P_{i j}(j=1, \ldots, m)$ be the weight of the alternatives $j$ with respect to criteria $i$. The magnitude of relative importance of alternative $j\left(R_{j}\right)$ is

$$
R_{j}=\sum_{i=1}^{n} C_{i} P_{i j}^{i=1}
$$

$R_{j}^{\prime} \mathrm{s}$ can be then used to rank-order alternatives.

AHP employs two types of measurement: relative measurement and absolute measurement. In relative measurement, paired comparisons are performed throughout the hierarchy, including the alternatives in the lowest level of the hierarchy with respect to the criteria in the level above. In 
absolute measurement, paired comparisons are also performed through hierarchy with the exceptions of the alternatives themselves. The alternatives are not pairwise compared, but simply rated with standard scale as to which category they fall under each criterion (Saaty, 1990). Absolute measurement needs to be given a standard scale with a unit. For example, in the evaluation of employee performance, the criteria of the best grade must be more than 80 and we know that the standard scale is 80 (Saaty, 1990).

\section{Decision model}

\subsection{The assumptions of the decision model}

The maximum value of alternatives could not surpass the weight of criteria. If an alternative is extremely important, it should be excluded from the consideration set. For example, the malfunction of scheduling management system will cause fatal lost for the firm. Obviously, it should not be selected for outsourcing consideration. Therefore, we get the first assumption:

1. The value of evaluation of the alternatives cannot surpass the weight of the criterion immediately above.

The service providers conditions, for example, finance, technology and service, would affect the final decision of outsourcing. In general, the more service providers there are, the better the providers a company can get. We believe that more service providers will get into the market in the future. In the model, we do not include the factors of vendor provisionally we just consider the internal conditions of the firm. We conclude the second assumption:

2. Most of the vendors can offer the technology and services we need, and the price and quality are important.

\subsection{The factors of outsourcing}

When we construct the AHP model, the first thing is to look for the factors. Saaty (1990) thinks that the most creative task in making a decision is to choose the factors that are important for that decision. In the outsourcing consideration, it means to find out those factors that affect the benefits of the firm. Several factors were used before, such as transaction cost economics (Aubert et al., 1996), and strategy or commodity (King, 1994; Quinn \& Hilmer, 1994). Some researchers suggested that the factors should be critical, economics and technology (Lacity et al., 1996) or technology, project management, business focus and organization (Buck-lew, 1992). Other researchers argued that firms can enhance the productivity and improve quality by outsourcing the IS function (McFarlan \& Nolan, 1995; Perry \& Devinney, 1997). Different organizations should have different considerations. Firms should include all factors which can affect organizations benefit as possible as they can. A careful examination of those factors mentioned above concludes that five dimensions or factors, management, strategy, technology, economics and quality, should be employed. Distinct attributes of these factors exist, as shown in Table 4. Firms should increase or decrease the attributes that are suitable for them while they make decisions.

For management, the problems that have to be dealt with include: insufficient performance of IS department, communication problems and selfishness between IS department and operational 
Table 4

The factors and attributes of outsourcing ${ }^{\mathrm{a}}$

Management

- Stimulate IS department to improve their performance and enhance morale

- Improve communication problems and selfishness between IS department and operational department

- Solve the floating and scarcity of employee

- Increase the ability of management and control of IS department

- Keep the flexibility to adjust department, including consolidation or decentralization

Strategy

- Focus on core competence

- Make strategic alliance with vendor to make up the shortage of resources or technology

- Form a new company by concatenating core competencies of these strategic alliances to develop new product and sell.

- Share the risks

- Time to market

Technology

- Get new technology

- learn new technology of software management and development from vendors

Economics

- Reduce the developing and maintaining cost of information systems

- Make the fixed costs to become to variable costs

- Increase the flexibility in finance

Quality

- Procure higher reliability and performance of IS

- Reach higher service level

a (Sources: Buck-lew, 1992; Loh \& Venkatraman, 1992; Lacity \& Hirschheim, 1993; Grover et al., 1994; Quinn \& Hilmer, 1994; Takac, 1994; Cross, 1995; Alexander \& Young, 1996; Jones, 1997).

department, the floating and scarcity of employee, not any commitment from IS department and distrust in the abilities of IS department, etc. The management can improve the performance of IS department, enhance morale and reengineering the organization by outsourcing IS functions, or even by threatening outsourcing all the IS department. It has been regarded as an effective means of management by the high management level.

For strategy, firms need to focus on their core activities and outsource noncore activities. In addition, the firms can make strategic alliance with vendors to make up the shortage of resources or technology. Some strategic alliances even form a new company by concatenating core competencies of these firms to develop and market new products. Other strategic considerations include sharing the risks and accelerating the time of product to market.

For technology, the fastest and most effective way to get the newest technology of IT is to outsource. In-house workers can learn new technology of software management and development from the vendor.

For economics, the major consideration of a company is to reduce the development and maintenance costs of information systems. Because of the scale of economics vendors have invested 
in the hardware, software and human resources, the costs can be reduced. Meanwhile, vendors may have a better management skill as well as higher productivity per employee, which will reduce costs. Another consideration of economics is financial flexibility. Because of outsourcing, the facilities and employee would be transferred to the vendor side, which transform fixed costs into variable costs, resulting in increasing financial flexibility.

For quality, most management believe that there should be a significant difference in the quality of service provided by the outsourcing vendors as opposed to the internal IS department (Gupta $\&$ Gupta, 1992). To the best knowledge of the authors, there are no empirical study to show that the quality of IS developed by outside vendors would be better than that of internal IS department. Nevertheless, good quality of service and good relationship are the significant success factors of outsourcing (Grover et al., 1996). To ensure high reliability and excellent performance of IS and good service quality, firms must set up the performance goals and service levels in contracts.

\subsection{The decision model and example}

In this section, we illustrate the model building process by an example. The model makes use of AHP and employs the following factors: management, strategy, technology, economics and quality. Every factor has some attributes that can explain its importance.

The model would be established in five steps as follows:

(a) Establish the expert team.

(b) Choose the factors and attributes.

(c) Construct the analytical hierarchy.

(d) Compute the alternatives.

(e) Make decision.

Example. Suppose a business bank wants to outsource part of IS functions. They think about the cost and management issues and want to know how to decide which systems should be outsourced first.

The candidate systems for outsourcing are facilities management (network facilities, host and some PCs), maintenance of management information system (the online transaction processing system, including little modification) and new system development (including internet homepage, unmanned bank and interactive voice response system). The vice president convenes a meeting and organizes an outsourcing task force to study and suggest the courses of action.

The leader of the task force is the vice president, while members include IS department manager, a senior engineer, business department manager, finance department manager, planning department manager and professional consultant. After some discussion, they employ the AHP method in the decision process.

Since many factors and attributes would affect the decision of outsourcing, the task force employs the outsourcing decision model and refers to Table 4 in choosing the attributes that would influence the decision. After some debate, the task force depicts a hierarchy structure as shown in Fig. 1.

Following the computing method described in AHP and the steps we offered, these experts began to compare the factors of the first level of the structure. After that, they got the square matrix 


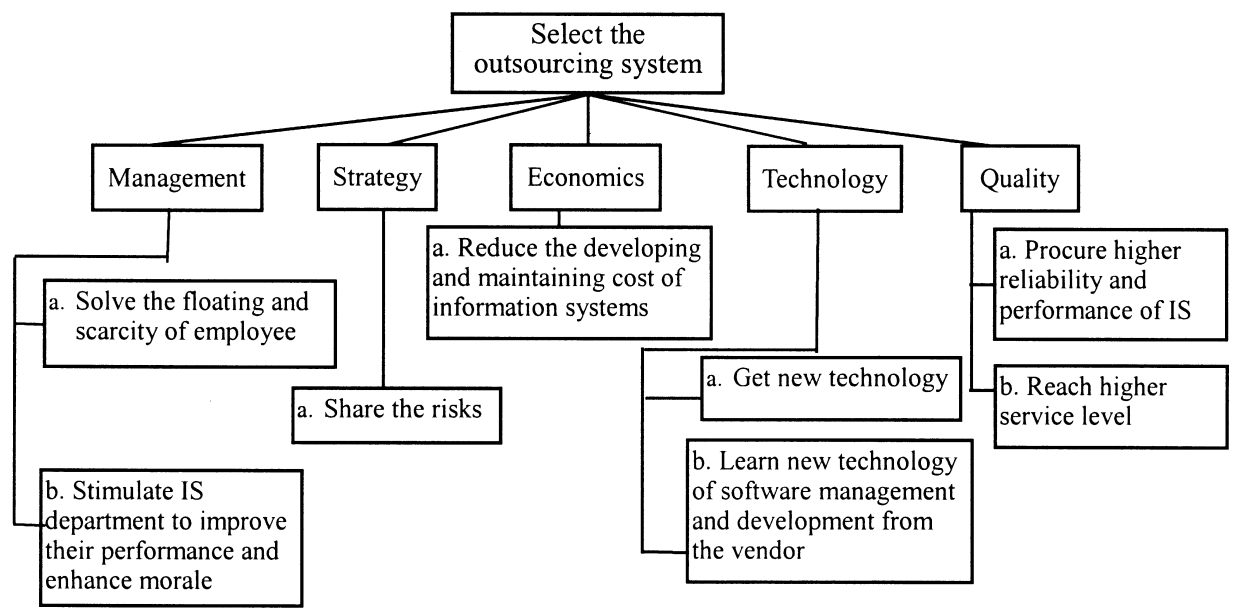

Fig. 1. The structure of the outsourcing problem.

Table 5

The square matrix of the first level

\begin{tabular}{llllll}
\hline & Management & Strategy & Economics & Technology & Quality \\
\hline Management & 1 & 1 & 4 & 5 & 3 \\
Strategy & 1 & 1 & 2 & 6 & 3 \\
Economics & $1 / 4$ & $1 / 2$ & 1 & 3 & 1 \\
Technology & $1 / 5$ & $1 / 6$ & $1 / 3$ & 1 & $1 / 2$ \\
Quality & $1 / 3$ & $1 / 3$ & 1 & 2 & 1 \\
\hline
\end{tabular}

as shown in Table 5 and the eigenvector of the maximum eigenvalue is $(0.35,0.32,0.11,0.07,0.15)$. We can find that the most important factor for outsourcing IS functions is their internal management problems.

The decision team continues to compute the weight of the next level by computing their eigenvalue and eigenvector. The square matrix that derived by pairwise comparison is expressed in Table 6 . These eigenvectors are $(0.67,0.33),(0.75,0.25)$ and $(0.8,0.2)$ individually. Fig. 2 represents the result until now.

The final level of this structure is the three alternatives that were selected to be considered for outsourcing. Two kinds of evaluation methods could be used. If we chose the absolute measurement, we need a measurement unit such as ranking from 1 to 5 (very weak, weak, common, good, very good) with a standard scale or utility values. If we use the relative measurement, we compare the importance of the three alternatives and compute its eigenvectors.

The weights of the three alternatives are represented in Table 7 using the relative measurement. Finally, we get the scores which are $0.24,0.39$ and 0.37 . The priorities for outsourcing the three IS 
Table 6

The square matrix of the second level

\begin{tabular}{lll}
\hline & Management-a & Management-b \\
\hline Management-a & 1 & 2 \\
Management-b & $1 / 2$ & 1 \\
\hline & Technology-a & Technology-b \\
\hline Technology-a & 1 & 3 \\
Technology-b & $1 / 3$ & 1 \\
\hline & \\
\hline Quality-a & Quality-a & Quality-b \\
Quality-b & 1 & 4 \\
\hline
\end{tabular}

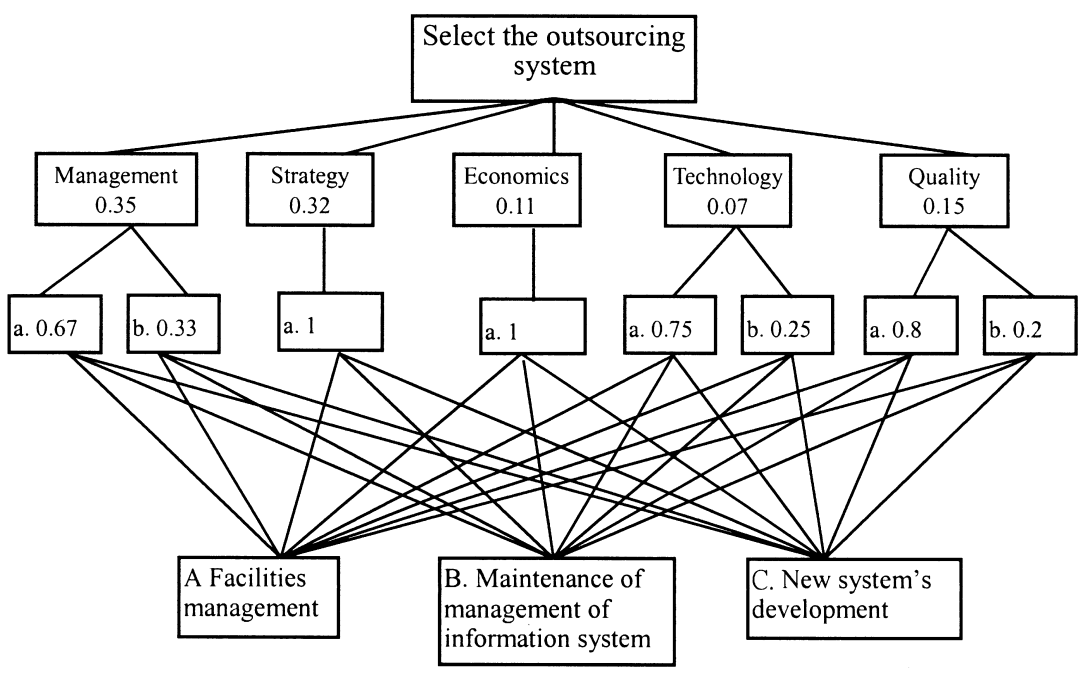

Fig. 2. The weights of the attributes.

are in the following order: the maintenance of management of information system, new systems development and facilities management.

If we use the absolute measurement with rank from 1 to 5 , Table 8 is the result. We obtain the final scores 2.26, 3.70 and 3.39. If the team think that 2.5 is the lowest score they could outsource their systems, we know that the maintenance of management information system and new systems development would be outsourced. If the lowest score is 3.5, only the maintenance of management information system is the candidate. 
Table 7

The total weights (relative measurement) ${ }^{\mathrm{a}}$

\begin{tabular}{|c|c|c|c|c|c|c|c|}
\hline \multirow[t]{2}{*}{$\begin{array}{l}\text { Factors and } \\
\text { attributes }\end{array}$} & \multirow[t]{2}{*}{ Weight } & \multicolumn{2}{|c|}{ A. Facilities management } & \multicolumn{2}{|c|}{$\begin{array}{l}\text { B. Maintenance of } \\
\text { management of } \\
\text { information system }\end{array}$} & \multicolumn{2}{|c|}{$\begin{array}{l}\text { C. New systems } \\
\text { developement }\end{array}$} \\
\hline & & Rank & Weight $\times$ Rank & Rank & Weight $\times$ Rank & Rank & Weight $\times$ Rank \\
\hline $\mathrm{M}-\mathrm{a}$ & $(0.35) \times(0.67)$ & 0.42 & 0.10 & 0.45 & 0.11 & 0.13 & 0.03 \\
\hline $\mathrm{M}-\mathrm{b}$ & $(0.35) \times(0.33)$ & 0.23 & 0.03 & 0.32 & 0.04 & 0.45 & 0.05 \\
\hline $\mathrm{S}-\mathrm{a}$ & $(0.32) \times 1$ & 0.05 & 0.02 & 0.33 & 0.11 & 0.62 & 0.20 \\
\hline $\mathrm{E}-\mathrm{a}$ & $(0.11) \times 1$ & 0.41 & 0.05 & 0.49 & 0.05 & 0.10 & 0.01 \\
\hline $\mathrm{T}-\mathrm{a}$ & $(0.07) \times(0.75)$ & 0.06 & 0.00 & 0.26 & 0.01 & 0.68 & 0.04 \\
\hline $\mathrm{T}-\mathrm{b}$ & $(0.07) \times(0.25)$ & 0.33 & 0.01 & 0.22 & 0.00 & 0.45 & 0.01 \\
\hline $\mathrm{Q}-\mathrm{a}$ & $(0.15) \times(0.8)$ & 0.21 & 0.03 & 0.54 & 0.06 & 0.25 & 0.03 \\
\hline $\mathrm{Q}-\mathrm{b}$ & $(0.15) \times(0.2)$ & 0.54 & 0.02 & 0.31 & 0.01 & 0.15 & 0.00 \\
\hline Total & & & 0.24 & & 0.39 & & 0.37 \\
\hline
\end{tabular}

${ }^{a}$ M: Management; S: Strategy; E: Economics; T: Technology; Q: Quality.

Table 8

The Total Weight (absolute measurement) ${ }^{\mathrm{a}}$

\begin{tabular}{|c|c|c|c|c|c|c|c|}
\hline \multirow[t]{2}{*}{$\begin{array}{l}\text { Factors and } \\
\text { attributes }\end{array}$} & \multirow[t]{2}{*}{ Weight } & \multicolumn{2}{|c|}{ A. Facilities management } & \multicolumn{2}{|c|}{$\begin{array}{l}\text { B. Maintenance of } \\
\text { management of } \\
\text { information system }\end{array}$} & \multicolumn{2}{|c|}{$\begin{array}{l}\text { C. New systems } \\
\text { development }\end{array}$} \\
\hline & & Rank & Weight $\times$ Rank & Rank & Weight $\times$ Rank & Rank & Weight $\times$ Rank \\
\hline $\mathrm{M}-\mathrm{a}$ & $(0.35) \times(0.67)$ & 3.00 & 0.70 & 4.00 & 0.94 & 2.00 & 0.47 \\
\hline $\mathrm{M}-\mathrm{b}$ & $(0.35) \times(0.33)$ & 2.00 & 0.23 & 4.00 & 0.46 & 4.00 & 0.46 \\
\hline $\mathrm{S}-\mathrm{a}$ & $(0.32) \times 1$ & 1.00 & 0.32 & 3.00 & 0.96 & 5.00 & 1.60 \\
\hline $\mathrm{E}-\mathrm{a}$ & $(0.11) \times 1$ & 4.00 & 0.44 & 4.00 & 0.44 & 1.00 & 0.11 \\
\hline $\mathrm{T}-\mathrm{a}$ & $(0.07) \times(0.75)$ & 1.00 & 0.05 & 2.00 & 0.11 & 5.00 & 0.26 \\
\hline $\mathrm{T}-\mathrm{b}$ & $(0.07) \times(0.25)$ & 2.00 & 0.04 & 4.00 & 0.07 & 4.00 & 0.07 \\
\hline $\mathrm{Q}-\mathrm{a}$ & $(0.15) \times(0.8)$ & 3.00 & 0.36 & 5.00 & 0.60 & 3.00 & 0.36 \\
\hline $\mathrm{Q}-\mathrm{b}$ & $(0.15) \times(0.2)$ & 4.00 & 0.12 & 4.00 & 0.12 & 2.00 & 0.06 \\
\hline Total & & & 2.26 & & 3.70 & & 3.39 \\
\hline
\end{tabular}

${ }^{a}$ M: Management; S: Strategy; E: Economics; T: Technology; Q: Quality.

\section{Discussion and conclusion}

The most important consideration when firms think about outsourcing is the benefits that the firms could obtain. Outsourcing firms benefit from cost savings, strategic fitness, improved management effectiveness, technology upgrade, and the service quality of IS. Moreover, one needs an 
operational decision model that can offer systematic steps and quantitative results to increase the precision of decision-making.

This research argues that firms need to consider more dimensions, including management, strategy, economics, technology and quality factors and their attributes. Meanwhile, we offer a decision model to help the practitioners make better decisions. There are two types of measurements, relative and absolute, to help managers make decisions. Each type of measurement can be used under different circumstances. When we do not know which system can get the benefits from outsourcing, absolute measurement is appropriate. We can then outsource systems with scores higher than the standard scale we gave. If we do not have sufficient resources and need to outsource several systems, relative measurement can be employed to determine the priorities.

This paper offers a decision model to help practitioners choose and analyze factors and attributes easily. Because it is a quantitative process, the practitioners can make better decisions and obtain better results from outsourcing.

Subjects deserving further investigation include vendor selection, management and control of outsourcing process. These crucial factors might affect the result enormously. Many issues are involved in outsourcing, such as total or partial outsourcing or strategic alliance. These issues are not included in our research, but they are important and should not be ignored by practitioners.

\section{References}

Alexander, M., \& Young, D. (1996). Strategic outsourcing. Long Range Planning, 29(1), 116-119.

Altinkemer, K., Chaturvedi, A., \& Gulati, R. (1994). Information systems outsourcing: Issues and evidence. International Journal of Information Management, 14, 252-268.

Arnett, K. P., \& Jones, M. C. (1994). Firms that choose outsourcing: A profile. Information \& Management, $26,179-188$.

Arrow, K. J. (1969). The organization of economic activity: Issues pertinent to the choice of market versus nonmarket allocation. The analysis and evaluation of public expenditure: the PPB system, vol. 1, (pp. 59-73). US Washington, DC: Government Printing Office.

Aubert, B. A., Rivard, S., \& Patry, M. (1996). A transaction cost approach to outsourcing behavior: Some empirical evidence. Information \& Management, 30, 51-64.

Bourassa, N. (1998). Outsourcing IT: Achieving maximum technology and business benefits. CMA Magazine, 72(4), 21-23.

Buck-lew, M. (1992). To outsource or not. International Journal of Information Management, 12, 3-20.

Caldwell, B. (1995). Outsourcing megadeals. Informationweek, 552, 34-40.

Coase, R. H. (1937). The nature of the firm. Economica, 4, 386-405.

Cross, J. (1995). IT outsourcing: British petroleums competitive approach. Harvard Business Review, 73(3), 94-102.

DGBAS (1998), The Status Report of Computer Applications in Taiwan, DGBAS.

Dietrich, M. (1994). Transaction cost economics and beyond: Towards a New Economics. New York: Routledge.

Flanagan, P. (1999). To keep sites performing, expect the unexpected. Business Communications Review, 29(9), 54-58.

Grover, V., Joong, M., Cheon, \& Teng, J. T. (1994). A descriptive study on the outsourcing of information systems functions. Information \& Management, 27, 33-44.

Grover, V., Joong, M., Cheon, \& Teng, J. T. (1996). The effect of service quality and partnership on the outsourcing of information systems functions. Journal of Management Information Systems, 12(4), 89-116.

Gupta, U. G., \& Gupta, A. (1992). Outsourcing the IS function. Information Systems Management, 9(3), 44-50.

Harker, P. T. (1989). The art and science of decision making: The analytic hierarchy process. The analytic hierarchy process application and studies, Berlin: Springer.

Jones, W. (1997). Outsourcing basics. Information Systems Management, 14(1), 66-69.

Ketler, K., \& Walstrom, J. (1993). The outsourcing decision. International Journal of Information Management, 13, 449-459. 
King, W. R. (1994). Strategic outsourcing decisions. Information Systems Management, 58-61.

Klepper, R., \& Jones, W. O. (1998). Outsourcing information technology, systems and services. Englewood cliffs, NJ: Prentice-Hall.

Lacity, M. C., \& Hirschheim, R. (1993). Information systems outsourcing: Myths, metaphors and realities. New York: Wiley. Lacity, M. C., Willcocks, L. P., \& Feeny, D. F. (1996). The value of selective IT sourcing. Sloan Management Review, 37(3), $13-25$.

Loh, L., \& Venkatraman, N. (1992). Determinants of information technology outsourcing. Journal of Management Information Systems, 9(1), 7-24.

McFarlan, F. W., \& Nolan, R. L. (1995). How to manage an IT outsourcing alliance. Sloan Management Review, 36(2), 9-23.

Murphy, C., Ker, S., \& Ross, L. M. (1999). U.S. and worldwide outsourcing market and trends, 1998-2003. IDC \# W19322.

Ngwenyama, O. K., \& Bryson, N. (1999). Making the information systems outsourcing decision: A transaction cost approach to analyzing outsourcing decision problems. European Journal of Operational Research, 115, 351-367.

Perry, W., \& Devinney, S. (1997). Achieving quality outsourcing. Information Systems Management, 14(2), 23-26.

Quinn, J. B. (1999). Strategic outsourcing: Leveraging knowledge capabilities. Sloan Management Review, 40(4), 9-21.

Quinn, J. B., \& Hilmer, F. B. (1994). Strategic outsourcing. Sloan Management Review, 35(4) 43-55.

Rosenthal, D. S., \& Jategaonkare, V. A. (1995). Wanted: Qualified IS professionals. Information Systems Management, 12(2), 27-31.

Saaty, T. L. (1980). The analytic hierarchy process: Planning, priority setting, resource allocation. New York: McGraw-Hill.

Saaty, T. L. (1990). How to make a decision: The analytic hierarchy process. European Journal of Operational Research, 48, 9-26.

Slaughter, S., \& Ang, S. (1996). Employment outsourcing in information systems. Communication of ACM, 39(7), 47-54.

Smith, M. A., Mitra, S. A., \& Narasimhan, S. (1998). Information systems outsourcing: A study of pre-event firm characteristics. Journal of Management Information Systems, 15(2), 61-93.

Takac, P.F. (1994). Outsourcing: A key to controlling escalating IT cost? International Journal of Technology Management, 9(2), 139-155.

Venkatesan, R. (1992). Strategic sourcing: To make or not to make. Harvard Business Review, 70(6), 98-107.

Williamson, O. (1975). Markets and hierarchies: Analysis and antitrust implications, a study in the economics of internal organization. New York: The Free Press.

Williamson, O. (1979). Transaction cost economics: The governance of contractual relations. Journal of Law and Economics, 22(2), 233-261.

Williamson, O. (1985). The economic institutions of capitalism: Firms, markets, relational contracting. New York: The Free Press.

Willcocks, L., Lacity, M., \& Fitzgerald, G. (1995). Information technology outsourcing in Europe and the USA: Assessment issues. International Journal of Information Management, 15(5), 333-351.

Chyan Yang is a professor in the Institute of Business and Management at National Chiao Tung University, Taipei, Taiwan. He holds a Ph.D. in Computer Science from University of Washington. He is also a senior member of the IEEE. His current research involves information management, industrial engineering and management, and electronic commerce.

Jen-Bor Huang is currently a doctoral candidate in the Institute of Business and Management at National Chiao Tung University, Taipei, Taiwan. He received his B.S. degree in applied mathematics and M.S. degree in computer engineering at National Chiao Tung University. His current research involves management information system and software development process. 